\title{
EDUCAÇÃO AMBIENTAL NO ENTORNO DA RESERVA BIOLÓGICA DE PEDRA TALHADA
}

\author{
José Rodrigo de Araújo Guimarães ${ }^{1}$
}

\author{
Anita Studer ${ }^{2}$
}

\author{
Cauê Trivellato 3
}

\begin{abstract}
RESUMO
Poderá A Reserva Biológica de Pedra Talhada, situada nos municípios de Quebrangulo no estado de Alagoas e Lagoa do Ouro no estado de Pernambuco, é uma área de mata atlântica de extrema importância para a região devido a sua rica biodiversidade biológica e a presença de nascentes que abastecem alguns municípios, no entanto vem sofrendo interferência antrópica negativa. Com objetivo de expandir o conhecimento e sensibilizar a rede pública de ensino e as populações dos municípios do entorno sobre a conservação desta área, o presente trabalho apresenta o resultado de um projeto de educação ambiental que se desenvolveu baseado na metodologia da pesquisa-ação nos municípios de Quebrangulo/AL e Correntes/PE. Neste sentido, o projeto resultou na participação ativa de 7.958 estudantes da rede pública de ensino, professores e aproximadamente 520 pessoas da sociedade civil, através de associações, sindicatos, pastorais, e outros atores locais. Os resultados mostram que, com o desenvolvimento do projeto e partilha do conhecimento científico associado ao conhecimento tradicional, a comunidade estudantil realizou discussões sobre a importância desta reserva e como preservá-la para a manutenção da biodiversidade, trazendo benefícios na diversidade de saberes com a implementação do ensino e da formação na cidadania sócio ambiental das comunidades do entorno.
\end{abstract}

PALAVRAS-CHAVE:Educação. Meio ambiente. Preservação.

\section{ENVIROMENTAL EDUCATIÓN ARROUND BIOLOGICAL RESERVE AT PEDRA TALHADA}

\author{
ABSTRACT \\ The Biological Reserve of PedraTalhada, located in the Quebrangulo municipality at Alagoas (AL) state and Lagoa \\ do Ouro at Pernambuco (PE) state, is an area of Atlantic forest that has a furthest importance to this region due

\footnotetext{
${ }^{1}$ Engenheiro Agrônomo, Mestrando em Agronomia - Faculdade de Ciências Agronômicas/UNESP, Campus de Botucatu-SP. rodrigoagronomoal@yahoo.com.br

${ }^{2}$ Bióloga, Doutora em Ciências - Fundadora e Presidenta Internacional da Associação Nordesta Reflorestamento e Educação, Genebra/Suiça. nordesta@nordesta.org.

${ }^{3}$ Agroecólogo, Mestrando em Agronomia - Faculdade de Ciências Agronômicas/UNESP, Campus de Botucatu-SP.Caue.trivellato@gmail.com
} 
its rich biological diversity and the presence of water source that supply some municipalities, however, has been suffered negative human interference. Aiming to expand the knowledge and to sensitize the peoples from municipalities about the conservation of this area, this paper presents the results of an environmental education project that was developed based on the methodology of research-action in the municipalities of Quebrangulo/AL and Chains/PE. In this sense, the project has resulted in the active participation of 7.958 students from public schools, teachers and approximately 520 people from civil society, through associations, unions, pastoral and other local actors. The results has been showed that with the project development and sharing of scientific knowledge related to traditional knowledge, the student community held discussions on the importance of this reserve and how to preserve it for the maintenance of biodiversity, bringing benefits in the diversity of knowledge with the implementation education and training in citizenship social-environmental of surrounding communities.

KEY-WORDS:Education. Environment. Preservation.

\title{
EDUCACIÓN AMBIENTAL EN LOS AREDORES DE LA RESERVA BIOLÓGICA DE PEDRA TALHADA
}

\begin{abstract}
RESUMEN
La reserva biológica de Pedra Talhada es localizada enlosmunicipios de Quebrangulo enlaprovincia de Alagoas y Lagoa do Ouro enlaprovincia de Pernambuco. Es una área de mata atlánticamuy importante para laregión, debido a sugrandiversidad biológica y laexistencia de manantiales que abastecen a variosmunicipios. Debido a lagraninterferencia negativa de lasactividadesdelhombre, sudiversidad está amenazada. Conel objetivo de ampliar elconocimiento y poder llamarlaatención de lared pública de enseñanza y de laspoblaciones de losmunicipios que laconforman, principalmente enlo que se refiere a laconservación y preservación de esta área. El presente trabajotuvo como objetivo principal formular y desarrollarunproyecto de educación ambiental utilizando lametodología de Pesquisa-Acciónenlosmunicipios de Quebrangulo/AL y Correntes/PE. Elproyecto conto conlaparticipación de 7958 estudiantes de lared de escuelas públicas locales, y con aproximadamente 520 personas de lasociedad civil, a través de asociaciones, sindicatos y otros atores socialeslocales. Los resultados obtenidosdemuestranque eldesarrollodelproyecto y el cambio de conocimiento científico y tradicional conlas personas, fuemuy importante para que ellosentiendanlanecesidad de preservar y conservar labiodiversidad biológica. Así como losbeneficiosenladiversidad cultural, o sea, ladiversidad de conocimiento, que es posibleconlaimplementación de enseñanza y formaciónsociales y ambientalesenlas comunidades del entorno.
\end{abstract}

PALABRAS-CLAVE:Educación. Medio ambiente. Preservación.

\section{INTRODUÇÃO}

A atual crise socioeconômica e ambiental instalada no planeta Terra está fazendo com que diversas iniciativas mitigadoras e transformadoras da realidade se desenvolvam a partir de iniciativas da sociedade de forma geral. Uma destas iniciativas se apresenta pelo significado do termo Educação Ambiental. Embora, para PELIZZOLI (2003), o substantivo educação dispensa o adjetivo ambiental, ao 
considerar que toda educação é ambiental porque não é possível uma educação fora do ambiente. No entanto, se esta afirmação transmitisse a realidade dos processos educativos mundiais, não haveria, possivelmente, a atual crise socioeconômica e ambiental.

Corroborando isto, PEDRINI (1988) se referindo a Conferência de Estocolmo, onde foi concebido o Plano de Ação Mundial e, apresentadas diretrizes para um Programa internacional de Educação Ambiental em 1972, diz que "pela primeira vez, a educação ambiental foi reconhecida como essencial para solucionar a crise ambiental internacional, enfatizando a necessidade de se reordenar as necessidades básicas de sobrevivência na Terra".

A Educação Ambiental é praticada desde os tempos remotos, recebendo diversas definições ao longo da história, conforme revisão histórica apresentada por ALVES (2007). Encontros promovidos pela Organização das Nações Unidas pela Educação, Ciência e Cultura - UNESCO e outros atores, a partir da Carta de Belgrado, resultado do Encontro Internacional de Educação Ambiental, na Iugoslávia em 1975, internacionalizaram este termo.

Consideremos a definição de REIGOTA (2009), que caracteriza a Educação Ambiental como uma educação política, visto que a mesma está comprometida com a ampliação da cidadania, da liberdade, da autonomia, e da intervenção direta dos cidadãos na busca de soluções e alternativas que permitam uma convivência digna e voltada para o bem comum.

Neste sentido, em 1985 é fundada a Associação NORDESTA Reflorestation\&Educationna cidade de Genebra/Suíça, com o objetivo de preservar o meio ambiente e melhorar as condições de vida das populações rurais inicialmente do Nordeste brasileiro, estando presente atualmente em 14 estados brasileiros. Esta associação é formada pela soma das ações de pessoas da sociedade civil apoiada por diversas entidades privadas de países europeus, e com parcerias públicas na Europa e no Brasil.

A percepção de que a preservação ambiental só pode ser realizada efetivamente e de forma duradoura com a participação das comunidades locais, sempre permeou a origem desta associação e de seus projetos, caracterizando-a 
como um agente de educação e preservação ambiental. $\mathrm{O}$ seu primeiro projeto no Brasil foi à dedicação exclusiva e o total apoio à criação da Reserva Biológica de Pedra Talhada, devido ao potencial biológico que esta possui e as espécies raras em extinção na lista vermelha. Desde meados da década de 1980, em paralelo a criação da reserva, os trabalhos de educação ambiental vêm sendo realizado na região através de palestras, diversas reuniões, passeatas, eventos educacionais, além de projetos sociais e de reflorestamento chegando a plantar 1.000 .000 de árvores em áreas desmatadas no município de Quebrangulo/AL.

Segundo a Política Nacional de Educação Ambiental - Lei n 9.795/1999, entende como educação ambiental como os processos por meio dos quais o indivíduo e a coletividade constroem valores sociais, conhecimentos, habilidades, atitudes e competências voltadas para a conservação do meio ambiente, bem de uso comum do povo, essencial à sadia qualidade de vida e sua sustentabilidade.

Ainda segundo PEDRINI (1998), afirma que:

É indispensável um trabalho de educação em questões ambiental, dirigindo, seja às gerações jovens, seja a adultos, o qual dê a devida atenção aos setores menos privilegiados da população, a fim de favorecer a formação de uma opinião pública bem informada e uma conduta dos indivíduos, das empresas e das coletividades, inspiradas no sentido de suas responsabilidades com a proteção e melhoria do meio, em toda a sua dimensão humana.

Neste sentido, a Associação NORDESTA desenvolveu um projeto de educação ambiental junto à população do entorno da Unidade de Conservação (UC), tipo Reserva Biológica de Pedra Talhada, localizada no nordeste brasileiro. Pela legislação nacional (Lei 9.985 de 2000), as reservas Biológicas pertencem à categoria de unidades de conservação de proteção integral. Têm como objetivo a preservação integral da biota e demais atributos naturais existentes em seus limites, sem interferência humana direta ou modificações ambientais, excetuando-se as medidas de recuperação de seus ecossistemas alterados e as ações de manejo necessárias para recuperar e preservar o equilíbrio natural, a diversidade biológica e os processos ecológicos naturais. A Reserva Biológica é de posse e domínio públicos. É proibida a 
visitação pública, exceto aquela com objetivo educacional, de acordo com regulamento específico.

A Reserva Biológica (Rebio) de Pedra Talhada foi criada em 1989 com área de 4.382,37 hectares divididos entre os estados de Alagoas e Pernambuco através do DECRETO № 98.524, DE 13 DE DEZEMBRO DE 1989(Figura 1).A região é caracterizada pelo clima tropical chuvoso, com duas estações bem definidas, verão seco (outubro a abril) e inverno chuvoso (maio a setembro), com médias pluviométricas anuais de 1.250 a $1.500 \mathrm{~mm}$, e temperaturas médias anuais em torno de $25^{\circ} \mathrm{C}$.

Figura 1: Imagem aéreo da Reserva Biológica de Pedra Talhada

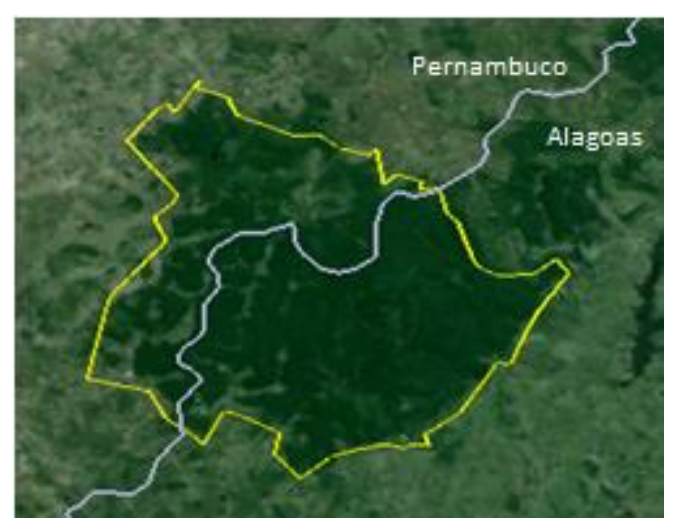

Fonte: Google Earth, 2013.

Segundo o Instituto Brasileiro de Meio Ambiente e Recursos Naturais Renováveis - IBAMA, a Unidade de Conservação Rebio de Pedra Talhada sofre grande pressão de invasores para a retirada ilegal de espécies arbóreas com valor econômico. Assim como a caça é uma atividade que continua sendo realizada por pessoas que residem na Reserva e no seu entorno, ocorrendo com maior frequência nos finais de semana, feriados e durante a noite. A espécie mais caçada pela população local é a paca. Em toda a unidade pode-se observar a "espera", estruturas de madeira montadas nas árvores para fazer tocaia para a caça.

De acordo com o Instituo Chico Mendes de Conservação da Biodiversidade ICMBio, existe nessa unidade de conservação seis espécies de animais ameaçadas protegidas, são elas: Gavião-pomba - Leucopternislacernulatus; Sabiazinha - 
Conopophagalineata; Formigueiro-de-cauda-ruiva - Myrmecizaruficauda; Uru-donordeste - Odontophoruscapueiraplumbeicollis; Pica-pau-anão-dourado Picumnusexilispernambucensis; e Cara-pintada - Phylloscartesceciliae, dentre outras.

Existem ainda 180 nascentes catalogadas que abastecem as barragens que fornecem água para as cidades de Quebrangulo, Palmeira dos Índios, Minador do Negrão e Estrela de Alagoas, pertencentes ao Estado de Alagoas e as cidades de Correntes e Lagoa do Ouro, pertencentes ao Estado de Pernambuco. Ou seja, esta Rebio é responsável pelo abastecimento de água a seis cidades, totalizando aproximadamente 139.309 habitantes (IBGE, 2013). Além destas cidades, mais dois municípios compõem o entorno da Rebio, inclusos no presente trabalho, sendo as cidades de Paulo Jacinto e Chã Preta, ambas do estado de Alagoas. Porém, inicialmente o projeto iniciou sua execução em Quebrangulo/AL e Correntes/PE, pretendendo-se ser realizado nos outros municípios do entorno.

Além destas características, a região possui diversos municípios integrantes do Território da Cidadania, dentro do Território da Mata Alagoana e do Território do Agreste. O programa de Territórios da Cidadania foi lançado em 2008 pelo Governo Federal, no âmbito do Ministério do Desenvolvimento Social e Combate a Fome MDS,com objetivo de promover o desenvolvimento econômico e universalizar programas básicos de cidadania por meio de uma estratégia de desenvolvimento territorial sustentável. Os territórios se caracterizam por um conjunto de municípios com o mesmo perfil econômico e ambiental, ter identidade e coesão social e cultural, havendo grande concentração de agricultores familiares e considera municípios e regiões que possuem baixo Índice de Desenvolvimento Humano (IDH) conforme informações do MDS. Diante deste contexto ambiental, socioeconómico e cultural, é de fundamental importância que projetos de educação ambiental sejam criados com objetivo de trocar conhecimento com a população que compõem o entorno da Rebio de Pedra Talhada.

Enfatizando esta importância, enquanto relação humana, GARAY e BECKER (2006), apresentam que a percepção humana do meio ambiente é função dos laços entre estímulos sensoriais, a estruturação cognitiva da informação e as modulações culturais, produzindo experiências e valores relativos a este meio ambiente. Existem 
ainda os processos psicológicos, as tradições sociais e valores culturais que afetam profundamente a percepção dos indivíduos em relação às espécies de um dado ecossistema.

Portanto, o presente trabalho mostra a construção e os resultados do projeto de Educação Ambiental no entorno da Rebio de Pedra Talhada, que teve como objetivo estabelecer um canal de comunicação entre os membros da Associação Nordesta Reflorestamento e Educação e do ICMBio - Instituto Chico Mendes de Conservação da Biodiversidade com as escolas dos municípios do entorno, buscando sensibilizar alunos, professores e a comunidade em geral sobre a importância da preservação desta reserva através do compartilhamento dos saberes adquiridos de pesquisadores de instituições nacionais e internacionais que desenvolveram estudos nesta área, além de ajudar na proteção contra a caça e o desmatamento.

\section{METODOLOGIA}

Para a construção deste projeto adotou-se a metodologia da pesquisa-ação, quando no início do projeto foram realizadas várias reuniões com professores dos municípios de Quebrangulo/AL e Correntes/PE pondo em destaque a conservação da reserva biológica de Pedra Talhada, principalmente no que diz respeito à caça e ao desmatamento, bem como em conscientizar as comunidades envolvidas da importância desta reserva para a região. As ideias e as sugestões foram anotadas e com isso organizou-se um plano de execução com a participação de todos os professores e alunos das redes de ensino municipal e estadual destes dois municípios, inicialmente.

Segundo Thiollent (2005), a pesquisa-ação deriva de uma pesquisa social cuja base empírica é realizada em paralelo com uma ação ou a resolução de um problema comum a todos os envolvidos.

Além disso, a pesquisa-ação tem como eixo principal a edificação do conhecimento coletivo, onde todos os envolvidos tem voz ativa (Gonzales, TozoniReis e Diniz, 2007). 
No primeiro instante do projeto na reunião com os coordenadores de escolas e diretores, foi apresentado a equipe da Associação Nordesta, que explicou os objetivos do projeto expressando que seria algo participativo onde todos teriam voz. Os professores, a partir deste momento seriam parceiros e ao longo de suas aulas levantariam questões sobre o nível de conhecimento dos alunos sobre a Rebio de Pedra Talhada e com isso traçaríamos as metas para elaboração de ações.

Como forma de avaliar a percepção dos professores foi realizado uma discussão dentro das reuniões sobre a Rebio de Pedra Talhada, e o resultado demonstrou que $80 \%$ já aviam visitado à reserva, porém desconheciam de alguns dados fundamentais sobre a rica fauna e flora, sobre as nascentes existentes e outros dados que as torna importante para a região.

A associação Nordesta distribui aos professores material didático a fim de ajudar no conhecimento das espécies de fauna e flora existentes na reserva, como forma de aprimorar seus conhecimentos para sensibilizar alunos. A partir daí o tema gerador foi definido: "A Reserva Biológica de Pedra Talhada". Pois, de acordo com Gonzalés, Tozoni-Reis e Diniz (2007) o tema gerador é aquele em que toda equipe mostra-se com interesse para entende-lo e com isso compreender a realidade.

Após esta etapa, foi elaborado um plano de ação através primeiramente do levantamento de todas as escolas existentes no município e assim determinar as atividades a serem desenvolvidas a partir dos dados obtidos nas pesquisas relacionadas ao conhecimento dos professores, alunos e comunidade sobre a reserva.

\section{RESULTADOS E DISCUSSÕES}

A partir do plano de ações foi realizado o levantamento da quantidade de escolas existentes nos municípios de Quebrangulo/AL e de Correntes/PE, municípios onde inicialmente desenvolveu-se este projeto. $O$ desenvolvimento do projeto incluiu a realização de palestras com o Tema: "A Reserva Biológica de Pedra Talhada", filmes educativos com temas relacionados à preservação do meio ambiente, aulas de campo com visitas as comunidades do entorno e shows musicais ecológicos com letras de 
músicas educativas objetivando a sensibilização dos alunos, constituindo a caravana ecológica.

Ao todo participaram das atividades do projeto 7.958 estudantes, sendo 4.830 do município de Correntes/PE e 3.128 do município de Quebrangulo/AL, contemplando toda a rede de ensino municipal e estadual destes municípios. Além dos professores, monitores, coordenadores, funcionários e pessoas das comunidades envolvidas de forma indireta.

As palestras ministradas pela equipe da Associação Nordesta foram realizadas durante um período de 14 meses iniciando em julho 2011 a novembro de 2012. O conteúdo das palestras mostraram dados obtidos a partir de pesquisas científicas realizadas ao longo de anos por pesquisadores na área de ornitologia, biologia, agronomia, hidrologia, dentre outros. Das quais destacam a relevante importância da rica biodiversidade existente nesta área de aproximadamente 4.500 hectares de mata atlântica, sendo considerada como um dos últimos resquícios desse bioma na região (Figura 2).

Figura 2: Palestra no Colégio Normal Municipal Dr. Antenor Alves Pedrosa Correntes/PE.

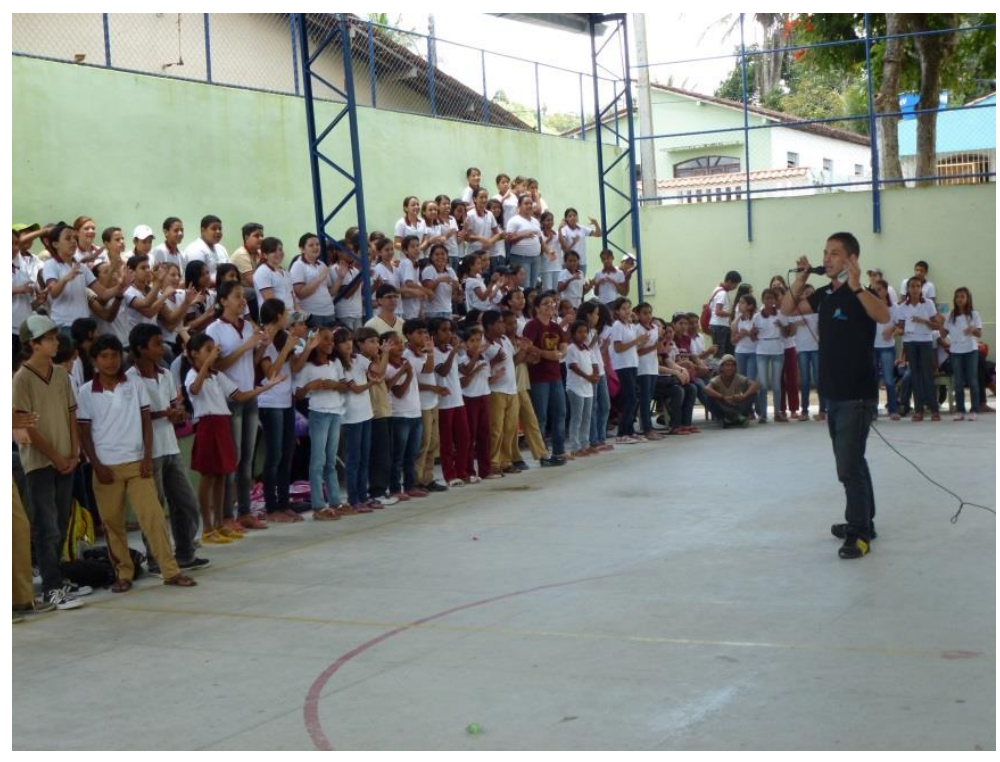

Fonte: NORDESTA, 2012.

Todo o material produzido precisa ter foco no repasse de conhecimento para os educadores das escolas. Pois, para que o professor tenha argumentos antes, durante e após uma visita de campo de uma determinada área que se quer estudar 
ou trabalhar, ele precisa do total conhecimento desta área (Carvalho, 1989; Benetti, 2002).

Uma das estratégias importantes dentro do programa de educação ambiental são as atividades de campo. Pois possibilita o contato de forma direta do aluno, tornando-o mais sensibilizado com os problemas ambientais de determinados lugares. Além disso, surgem as reflexões sobre o tema em questão ocasionando mudanças no comportamento e nas atitudes (Carvalho, 1998).

Como base de estudos e divulgação da importância da Reserva Biológica de Pedra Talhada foram elaborados e distribuídos materiais didáticos com ilustrações de animais em extinção que ainda habitam na reserva, como também descrições com ilustrações de árvores nativas da flora brasileira de importância ecológica, das nascentes que abastecem as barragens que fornecem água para as cidades do entorno dentre outros dados de fundamental importância para o conhecimento sócioeducativo da comunidade em geral e estudantil.

Segundo Colom (2004), a educação ambiental com a realização de trilhas ecológicas para o aprendizado é extremamente importante, pois proporciona a interação entre o sujeito e o meio ambiente juntamente com a percepção da realidade do local que é percebida como algo externo. Tal fato, mostra ao visitante que durante a trilha em uma unidade de conservação através do contato direto com os novos elementos pode-se perceber de acordo com a capacidade de interpretação pessoal a problematização do meio. Desse modo, o conhecimento é adquirido de acordo com a interpretação que o visitante tem no decorrer da trilha.

O projeto foi realizado nas escolas caracterizando-se como um momento de repasse do conhecimento, mas também de aprendizado através da troca de experiências e socialização repassadas pelos alunos, quando faziam relatos sobre alguns problemas vivenciados em seu dia a dia. Os palestrantes traziam 0 conhecimento científico associado ao conhecimento tradicional, com dados sobre a fauna, flora, recursos hídricos e a importância da preservação da reserva. Já os alunos e professores traziam as informações da realidade vivenciada no entorno da reserva, pois alguns moravam nessas localidades. Um dos pontos mais destacados 
entre os alunos eram a caça, o desmatamento e a comercialização de aves nas cidades da região, pois eram situações vivenciadas no decorrer do tempo.

No decorrer do desenvolvimento do projeto, com o repasse das informações e das possíveis consequências do desmatamento e da caça, os alunos e as comunidades participativas se integraram na divulgação da proteção e preservação da biodiversidade de Pedra Talhada(Figura 3). Passaram a partilhar fatos vivenciados em suas famílias tais como: o pai que apreendia pássaros, que caçava a noite ou desmatava para a venda ilegal de madeira, dentre outros problemas. Mas a partir do conhecimento adquirido sobre a importância que a biodiversidade tem para a vida e a sustentabilidade dos recursos naturais, obtivemos vários exemplos de alunos que conseguiram repassar para seus familiares às informações adquiridas e até convencer alguns a mudar hábitos e costumes como soltar aves que se encontravam presas em cativeiros ou gaiolas.

Figura 3: Palestra com moradores da área da reserva na Comunidade "João Ferreira".

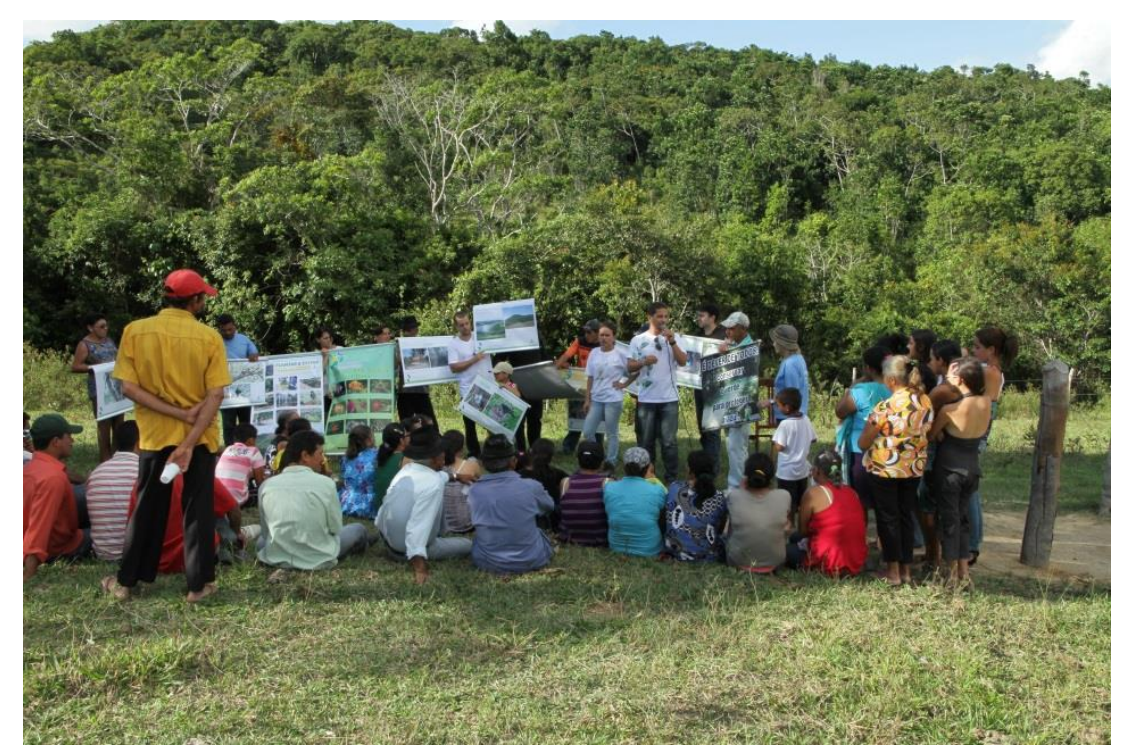

Fonte: NORDESTA, 2012.

Os materiais didáticos elaborados como base de dados distribuídos a todas as escolas e entidades participativas, estimularam ações de sensibilização da comunidade em geral, como o desenvolvimento de atividades realizadas em datas importantes no calendário ambiental, ações de conscientização a preservação 
ambiental, trabalhos de pesquisas educacionais sobre o tema proposto, passeatas e outros eventos voltados a esta área.

Para subsidiar o projeto, foi realizado no município de Quebrangulo, Estado de Alagoas, um concurso com o tema: "Água da minha cidade: da nascente a torneira" em março de 2013 como forma de difundir o conhecimento da origem da água que chega em suas casas, da importância da preservação das nascentes, na busca para o fortalecimento da consciência crítica sobre a necessidade da sustentabilidade como forma mais ampla, promovendo assim momentos de aprofundamento nas pesquisas, discussão e reflexão sobre o tema proposto. Esse concurso resultou em um grande evento aberto ao público realizado as margens de uma das barragens que abastece vários municípios da região, contando com a participação grandiosa de todos os alunos da rede pública de ensino, de funcionários públicos, autoridades locais e da comunidade geral, totalizando aproximadamente quatro mil pessoas. Os alunos expuseram seus trabalhos de pesquisa e foram selecionadas as melhores paródias sobre o tema lançado, tendo premiações para os de maior relevância.

De forma geral, os professores e representantes da sociedade declararam que esta oportunidade foi fundamental e única para a formação dos alunos, que em sua maioria conviveram com situações provindas de problemas de intervenção antrópica nas matas, destacando-se ações desta natureza, na reserva biológica de Pedra Talhada. Com a implementação e desenvolvimento deste projeto houve a motivação e a melhoria da prática pedagógica com temas voltados a este assunto, além da participação de um total de 7.958 estudantes da rede pública, cerca de 520 pessoas membros de associações, sindicatos e grupos comunitários também participaram deste projeto adquirindo e expandindo o conhecimento.

\section{CONCLUSÃO}

O presente projeto demonstrou, a partir dos resultados, que através da execução de ações participativas, das práticas e reflexões sobre o tema exposto, através também da música pode-se construir novos cidadãos munidos com 
conhecimentos sobre as coisas que os cercam, ajudando em seu comportamento e sua forma de agir.

A metodologia utilizada permitiu a junção de saberes e a implantação de ações interdisciplinar entre todas as escolas envolvidas e da comunidade em geral, melhorando o aperfeiçoamento dos profissionais da educação em relação ao tema gerado, visto que faz parte da ecologia de sua região, além de gerar reflexões e ações sobre como enfrentar e agir em situações do cotidiano.

Sendo assim, a proposta do presente projeto vem incrementar ações de que a educação ambiental venha a ser uma atividade extra sala de aula ocasionando a inserção da teoria com a prática no processo de transformação da realidade sócio ambiental. Promovendo melhorias na formação da cidadania na junção de atividades coletivas gerando mobilizações para a edificação e construção de uma sociedade sustentável.

\section{REFERÊNCIAS}

ALVES, L.S. A Educação Ambiental e a Pós-Graduação: Um olhar sobre a Produção Discente. Dissertação de Mestrado. Pontifícia Universidade Católica do Rio de Janeiro - PUC - Rio de Janeiro: 2007.

ASSOCIAÇÃO NORDESTA REFLORESTAMENTO E EDUCAÇÃO. Reserva de Pedra Talhada. Disponível em: <http://www.nordesta.org/pt/projetos/biodiversidade/reserva-de-pedratalhada.html>. Acesso em: 08 ago. 2014.

BENETTI, B. A temática ambiental e os procedimentos didáticos: perspectivas de professores de ciências. In: ENCONTRO PERSPECTIVAS DO ENSINO DE BIOLOGIA. 8, 2002, São Paulo. Anais...1 CD-ROM.São Paulo: FEUSP/USP, 2002.

BIODIVERSIDADE, Instituto Chico Mendes de Conservação da. Unidade de Conservação. Disponível

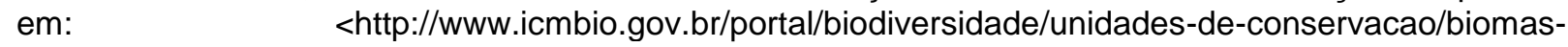
brasileiros.html>. Acesso em: 10 ago. 2014.

CARVALHO, I. C. M. Em direção ao mundo da vida: interdisciplinaridade e educação ambiental. (Cadernos de Educação Ambiental) Brasília: IPÊ - Instituto de Pesquisas Ecológicas, 1998.

CARVALHO, L. M. A temática ambiental e a escola do 1ำ grau. São Paulo, 1989. 286 f. Tese (Doutorado em Educação) - Faculdade de Educação, Universidade de São Paulo.

Casa Civil. Sistema Nacional de Unidades de Conservação da Natureza. 2000. Disponível em: <http://www.planalto.gov.br/ccivil_03/leis/19985.htm>. Acesso em: 08 ago. 2014.

COLOM, A. J. A (des) construção do conhecimento pedagógico: novas perspectivas para a educação. Porto Alegre: Artmed, 2004. 
FOME, Ministério do Desenvolvimento Social e Combate à. Territórios da Cidadania. Disponível em: <http://www.mds.gov.br/segurancaalimentar/desenvolvimentoterritorial/territorios-da-cidadania-1>. Acesso em: 10 ago. 2014.

GARAY, I. E.G, BECKER, B.K. As dimensões humanas da biodiversidade: 0 desafio de novas relações sociedade-natureza no século XXI. Petrópolis: Editora Vozes, 2006. 483p.

GONZALES, L. T. V.; TOZONI-REIS, M. F. C.; DINIZ, R. E. S. Educação ambiental na comunidade: uma proposta de pesquisa-ação. Revista Eletrônica Mestrado emEducação Ambiental, Rio Grande, v. 18, 2007. Disponível em <http:// www.remea.furg.br/edicoes/vol18/art31v18a27.pdf>. Acesso em: 21 abr. 2008.

Instituto Brasileiro de Geografia e Estatística. Cidades. Disponível em: <http://www.cidades.ibge.gov.br/xtras/home.php>. Acesso em: 06 ago. 2014.

Instituto Brasileiro de Meio Ambiente e dos Recursos Naturais Renováveis. Disponível em: <http://www.ibama.gov.br/ >. Aceso em: 10 ago. 2014.

PEDRINI, A.G. Educação Ambiental: reflexões e práticas contemporâneas. Rio de Janeiro: Vozes, 1988.

PELIZZOLI, M.L. Correntes da Ética Ambiental. Petrópolis, Vozes, 2003.

REIGOTA, M. O que é a Educação Ambiental. 2ed. São Paulo: Brasiliense, 2009.

THIOLLENT, M. Metodologia da pesquisa-ação. 14. ed. São Paulo: Cortez, 2005.

TOZONI-REIS, M. F. C. Pesquisa-ação: compartilhando saberes. Pesquisa e ação educativaambiental. In: FERRARO JR., L.A. (Org.). Encontros e caminhos: formação deeducadoras (es) ambientais e coletivo educadores. Brasília: Ministério do Meio Ambiente,2005. Disponível em: <http://mma.gov.br/port/sdi/ea/og/pog/arqs/encontros.pdf.> Acesso em: 12 abr. 2008. 